\title{
Assessing the presence of selection bias in meta-analyses of randomised trials using baseline heterogeneity
}

\author{
Laura Clark, Caroline Fairhurst, Catherine Hewitt, Yvonne Birks, Sally Brabyn, Sarah Cockayne, Sara Rodgers, \\ Katherine Hicks, Robert Hodgson, Elizabeth Littlewood, David Torgerson*
}

From 2nd Clinical Trials Methodology Conference: Methodology Matters

Edinburgh, UK. 18-19 November 2013

\section{Objective}

To assess the likelihood of biased trials contained in 12 recently published meta-analyses.

\section{Design}

A review of component randomised controlled trials of systematic reviews with 12 meta analyses.

\section{Data sources}

12 recently published systematic reviews with 503 component randomised trials, which were published in the BMJ, Lancet, JAMA and The Annals of Internal Medicine up until May 2012.

\section{Eligibility criteria for selecting studies}

Systematic reviews were eligible for inclusion if they included only randomised controlled trials (RCTs). We obtained the full text for the component RCTs of the 12 systematic reviews. We excluded RCTs which were not available in English from our review and analysis.

\section{Results}

Five of the 12 meta-analyses exhibited heterogeneity $\left(\mathrm{I}^{2}>0.30\right)$ in age differences, when there should have been none, with two having significant or substantial heterogeneity $\left(\mathrm{I}^{2}>0.50\right)$. In three meta-analyses we found that the age of intervention group was statistically significantly higher than in the control group. Two meta-analysis had a distribution of p-values that were inconsistent with chance. Meta-regression explained some of the observed heterogeneity in two meta-analyses as a consequence of poor allocation concealment.

University of York, York, UK

\section{Conclusions}

The majority of a sample of recent meta-analyses showed that there were signs of imbalance and or heterogeneity in ages between treatment groups, when there should have been none. Systematic reviewers might consider using the techniques described here to assess the validity of their findings.

Published: 29 November 2013

doi:10.1186/1745-6215-14-S1-096

Cite this article as: Clark et al:: Assessing the presence of selection bias in meta-analyses of randomised trials using baseline heterogeneity. Trials 2013 14(Suppl 1):096.
Submit your next manuscript to BioMed Central and take full advantage of:

- Convenient online submission

- Thorough peer review

- No space constraints or color figure charges

- Immediate publication on acceptance

- Inclusion in PubMed, CAS, Scopus and Google Scholar

- Research which is freely available for redistribution 